\title{
DYRP-VLC: Um Protocolo De Roteamento Dinâmico Para Redes De Comunicação Por Luz Visível
}

\author{
Luiz Eduardo Mendes Matheus ${ }^{1}$, Alex Borges Vieira ${ }^{1}$, \\ Marcos A. M. Vieira ${ }^{2}$ \\ ${ }^{1}$ Depto. de Ciência da Computação - Universidade Federal de Juiz de Fora (UFJF) \\ ${ }^{2}$ Depto. de Informática - Universidade Federal de Minas Gerais (UFMG) \\ luizmendes@ice.ufjf.br, alex.borges@ufjf.edu.br, mvieira@dcc.ufmg.br
}

Resumo. Na última década, o interesse em torno da Comunicação por Luz Visível (VLC) aumentou consideravelmente, devido a fatores como a crescente demanda por recursos sem fio na Internet e às vantagens oferecidas pela transmissão de dados através da luz visível. Entretanto, a utilização da luz como meio de comunicação apresenta diversos desafios como interferência e bloqueios criados por obstáculos. Ao mesmo tempo, diversos ambientes oferecem uma rica infraestrutura de fontes de luz, que podem ser utilizadas para auxiliar na comunicação, por exemplo, através de mecanismos de cooperação. Neste trabalho, foi apresentamos DYRP-VLC, um protocolo de roteamento dinâmico que tem como objetivo aumentar o desempenho de sistemas VLC em ambientes dinâmicos. DYRP-VLC reage a obstáculos, construindo rotas alternativas na rede. A avaliação do protocolo foi realizada em um ambiente real, utilizando a plataforma embarcada OpenVLC 1.0. Os resultados obtidos mostram que, usando o DYRP-VLC, a rede foi capaz de se adaptar a mudanças dinâmicas do ambiente de comunicação, como sombras e obstáculos. Assim, a rede manteve a comunicação ininterrupta, com uma sobrecarga negligenciável $(\approx 1 \%)$. Este trabalhou gerou 1 mini-curso, 2 artigos nacionais e 3 periódicos.

Palavras-chave: Comunicação por luz visível, VLC, roteamento reativo

\section{Introdução}

Comunicação por Luz Visível (VLC) é o nome dado ao tipo de comunicação em que se usa a faixa entre $380 \mathrm{~nm}$ a $750 \mathrm{~nm}$ do espectro eletromagnético para transmitir dados [Matheus et al. 2017]. Durante a última década, VLC tornou-se muito popular, tanto na academia, quanto na indústria. Em especial, parte do interesse em uma nova forma de comunicação sem fio se dá pelos desafios atuais, como por exemplo, a lotação do espectro eletromagnético destinada ao Wi-Fi (spectrum crunch) ${ }^{1}$ [De Vries et al. 2014]. Nesse sentido, o uso de luz visível para transmissão de dados foi considerado para uma ampla gama de aplicações tais como comunicação LED-LED [Matheus et al. 2018a], sistemas veiculares [Okada et al. 2009], sistemas de localização [Li et al. 2014] e comunicação subaquática comunicação [Kaushal and Kaddoum 2016].

De forma geral, sistemas VLC apresentam dois componente principais: um transmissor e um receptor. Os diodos emissores de luz (LEDs) são comumente usados nos transmissores. Porém, até mesmo a luz natural, como a luz solar, pode ser usada para

\footnotetext{
${ }^{1}$ Will we ever face a wireless "spectrum crunch"? - http://www.bbc.com/future/story/ 20131014-are-we-headed-for-wireless-chaos, 2013.
} 
este fim [Wang et al. 2016]. O transmissor é responsável por modular a intensidade da luz para transmitir dados. O receptor usa fotossensores para capturar a luz e converter em dados. Note que LEDs transmitem luz apenas em um campo de visão delimitado. Assim, transmissor e receptor devem estar alinhados para uma correta transmissão de dados.

Existem diversos desafios a serem tratados para uma efetiva comunicação por luz visível. O ambiente dinâmico criado pelas múltiplas fontes de luz, a interferência de fontes diversas e outros fatores como sombreamento e obstáculos podem ter um grande impacto no desempenho da comunicação [Xiang et al. 2014]. Por outro lado, a infraestrutura de iluminação existente oferece oportunidades para protocolos cooperativos de múltiplos saltos. Em suma, tão logo um dispositivo perca a linha de visão durante a comunicação, ele pode recorrer aos demais dispositivos existentes no meio para fazer uma comunicação indireta. Dessa forma, a comunicação fim-a-fim não é interrompida.

Nesse sentido, apresentamos o DYRP-VLC ${ }^{2}$, um protocolo de roteamento dinâmico, multicamadas, que aumenta o desempenho de sistemas VLC em ambientes dinâmicos. DYRP-VLC reage às interrupções de comunicação fim-a-fim impostas por obstáculos, sombras ou mobilidade, construindo rotas alternativas na rede de luz visível, sem a necessidade de prévio conhecimento da topologia ou dos dispositivos que a compõem.

Existem trabalhos na literatura que abordam múltiplos saltos em VLC [Kim et al. 2016, Ahmad et al. 2017, Klaver and Zuniga 2015]. Porém, esses trabalhos preocupam-se, primordialmente, em possibilitar comunicação fim-a-fim sem linha de visão entre as entidades comunicantes. Mais ainda, necessitam do conhecimento da topologia da rede e do uso de retransmissores (relays) específicos. O foco principal destes trabalhos é, muitas vezes, aumentar a distância entre os nós. Não lidam com os aspetos dinâmicos da rede; não identificam a quebra da comunicação e não requisitam, dinamicamente, cooperação de seus pares. Em suma, não se adaptam as mudanças do ambiente de comunicação, como o surgimento de sombras e obstáculos.

Nós implementamos o DYRP-VLC no OpenVLC $1.0^{3}$, uma plataforma de código aberto, atual e bem conhecida, projetada para pesquisas em VLC. Avaliamos o novo protocolo em uma rede dinâmica, onde a comunicação é interrompida por interposição de obstáculos. Nossos resultados mostram DYRP-VLC possibilita comunicação fim-a-fim ininterrupta, mesmo em condições em que há obstáculos. Mais ainda, o novo protocolo apresenta baixa sobrecarga. De fato, o protocolo necessita de apenas $1 \%$ a mais de recursos, quando comparada a um protocolo que não trata comunicação com múltiplos saltos.

As principais contribuições dessa dissertação são:

- Um survey do estado da arte e disseminhação da linha de pesquisa no Brasil.

- A delimitação do desempenho de VLC usando LED como transmissor/receptor.

- O projeto e implementação de um protocolo de roteamento dinâmico, multi-camada, capaz de manter a comunicação VLC mesmo em ambientes com interrupção de visão entre os dispositivos.

- Proposta e avaliação de duas políticas de reação ao ambiente VLC.

- Aplicação e experimentação do protocolo dinâmico proposto em um ambiente real, utilizando dispositivos VLC embarcados amplamente usados em pesquisa pelo mundo.

\footnotetext{
${ }^{2}$ Acronônimo originado do Inglês: DYnamic Routing Protocol for $V$ isible Light Communication

${ }^{3}$ http://www.openvlc.org/home.html
} 


\section{Um Protocolo de Roteamento Dinâmico para VLC}

O DYRP-VLC é inspirado em protocolos de roteamento para MANETs (AODV, DSR). As redes de Comunicação por Luz Visível podem ter características semelhantes às redes ad-hoc móveis, em especial, por considerar mobilidade, largura de banda limitada, falta de confiabilidade e limitações da camada física. Além disso, obstáculos são fatores importantes em VLC. Eles podem surgir a qualquer momento e assim, interromper o campo de visão entre os dispositivos comunicantes.

Quando um nó deseja se comunicar com outro nó — que não está em sua tabela de roteamento- ele tenta construir uma rota. Se a rota é construída com sucesso, uma ligação bidirecional é criado entre eles. O DYRP-VLC apenas mantém informações de roteamento entre nós ativos. Ele não necessita ter conhecimento prévio da topologia e, portanto, tem uma vantagem considerável em termos de consumo de memória. Cada nó na rede apenas possui uma estrutura de dados que representa uma tabela de rotas.

O DYRP-VLC apresenta três principais blocos funcionais: (I) O mecanismo de construção de rotas; (II) o mecanismo de detecção de rotas quebradas; (III) o mecanismo de reação a rotas quebradas e; A seguir, detalhamos cada um desses blocos funcionais.

\subsection{Construção de rotas}

Toda vez que um nó recebe um pacote, ele procura o endereço de destino em sua tabela de roteamento. Se não encontrar, o processo de descoberta de rota será iniciado. Este processo envolve a transmissão de uma mensagem $R R E Q$ (requisição de rota), seguida pela espera por uma mensagem $R R E P$ (resposta de rota). Essas duas mensagens de roteamento compartilham a mesma estrutura, mas diferem na forma como são enviadas pela rede.

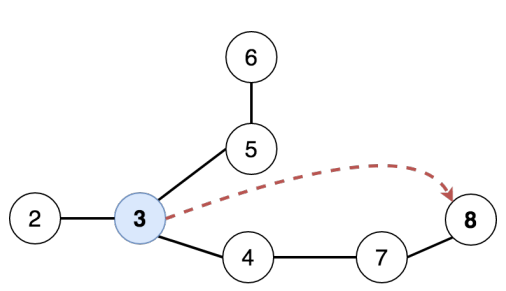

(a)

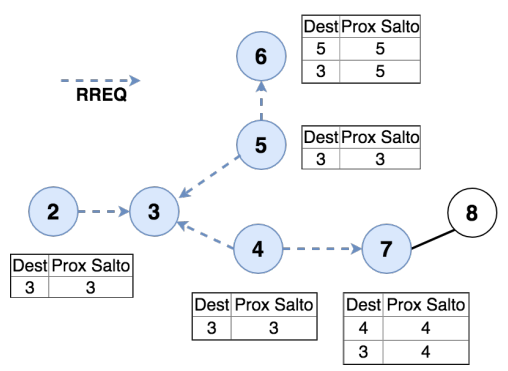

(c)

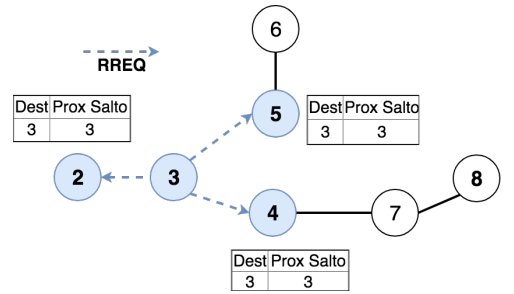

(b)

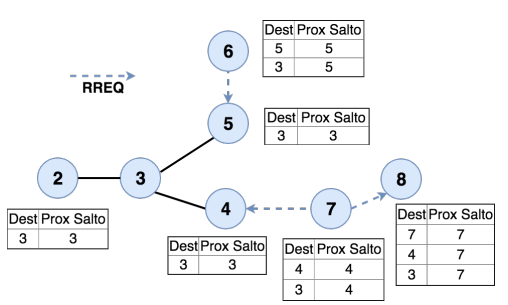

(d)

Figura 1. Descoberta de rota onde o nó 3 tenta se comunicar com o nó 8.

A construção de uma rota começa com um nó de origem transmitindo uma mensagem de solicitação de rota $(R R E Q)$ para encontrar um caminho válido para o destino (como mostra o exemplo na Figura 1). Cada nó intermediário salva uma rota em direção à origem e passa a mensagem adiante, por uma inundação a seus contatos. Quando o destino recebe o $R R E Q$, ele cria uma rota completa em direção ao nó de origem, uma vez que 
o destino conhece, agora, todos os nós intermediários pelos quais a mensagem passou. $\mathrm{O}$ nó destino pode então enviar uma mensagem de resposta de rota (RREP), que passa por cada nó presente no caminho exclusivo. Essa mensagem não é inundada na rede. Ela é enviada diretamente a cada nó pertencente a rota. Quando o nó de origem recebe o RREP, ele estabelece uma rota para o destino e começa a usá-la para enviar pacotes. Cada nó no caminho atua como nós de retransmissão nesse caso.

A descoberta de rota deve ser controlada para evitar loops e rotas obsoletas. Para isso, toda vez que um nó envia uma mensagem RREQ, ele aguarda a mensagem RREP por um período de tempo. Se o nó falhar ao criar uma rota bidirecional para o destino, ele tentará novamente por um determinado número de vezes. Ao final das tentativas, se uma rota não for descoberta, o nó terá que aguardar outro período até tentar novamente.

\subsection{Detecção e reação a rotas quebradas}

A qualquer momento, dado um parâmetro específico, o estado de determinada rota pode ser definido como quebrado. Isso acontece se algum nó não conseguir encaminhar o pacote até o destino. Se isso acontecer, o nó gera uma mensagem de erro RERR, que percorre o caminho até alcançar o nó de origem (Figura 2).

Um nó deve ser capaz de detectar quando o enlace está quebrado. Sistemas VLC são muito suscetíveis a interferências e, qualquer sombra ou movimento pode bloquear a comunicação. Para realizar a manutenção da rota, duas abordagens diferentes podem ser tomadas: usar contadores de referência ou usar tempo limite da rota. Contadores de referência dependem de informações baseadas na camada MAC ( número de pacotes perdidos ou errados). A segunda abordagem, apenas quebra a rota a cada intervalo de tempo. Nesse sentido, foram desenvolvidos dois mecanismos para detecção de quebra de rotas: DYRP-RC (contador de referências) e DYRP-RT (timeout de rotas).

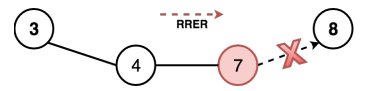

(a)

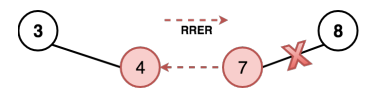

(b)

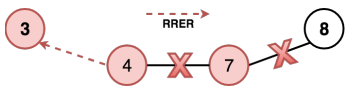

(c)

Figura 2. Exemplo de quebra de rota detectada pelo nó 7.

No DYRP-RC, o protocolo de roteamento está ciente da transmissão da camada MAC. Se o enlace for quebrado, eventualmente, o nó que envia o quadro não receberá seu $A C K$. DYRP-RC recolhe esta informação e quebra a rota existente. Se o $A C K$ não for recebido por um determinado período de tempo, o enlace será considerado quebrado e o $R E R R$ será enviado para o fluxo ascendente. No entanto, se a camada MAC receber um $A C K$ após uma certa quantidade de tentativas, a contagem será limpa e reiniciada.

Pelo DYRP-RT, consideramos que estamos lidando com um cenário muito dinâmico. Pode ocorrer perdas em rajadas mas, logo a seguir, o caminho fim-a-fim se reestabelece. Deixar que a camada inferior acione o mecanismo e informe que o enlace foi rompido pode causar falhas excessivas e sobrecarregar a rede com mensagens de erro e novas tentativas de descoberta de rota. Para evitar isso, esta solução explora o tempo limite da rota como o gatilho para interromper a rota e enviar RERR.

\section{Avaliação do DYRP-VLC}

O protocolo foi implementado e avaliado utilizando o OpenVLC 1.0 como base. O OpenVLC é uma das plataformas mais conhecidas do estado da arte para a realização de pes- 
quisas na área. A versão utilizada é estável e o seu desenvolvimento está ativo. No OpenVLC, a integração com a pilha de protocolos Linux permite a manipulação desde camada física a aplicações, além de validações com ferramentas bem aceitas pela comunidade.

Foram considerados dois cenários diferentes: estático e dinâmico. O cenário estático, apresentado na figura 3a, contém 4 nós. Esses nós são capazes de se comunicar apenas com seus vizinhos. O cenário dinâmico ${ }^{4}$, apresentado na figura $3 \mathrm{~b}, \mathrm{c}$ apresenta três nós com visão total entre eles. Nesse cenário, um objeto interrompe a comunicação entre dois nós e assim, avaliamos a dinâmica do protocolo proposto ( um vídeo de exemplo pode ser visto no link presente no rodapé).

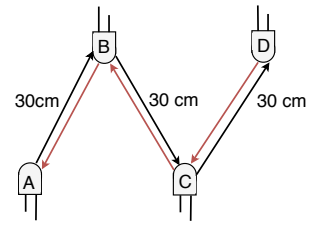

(a)

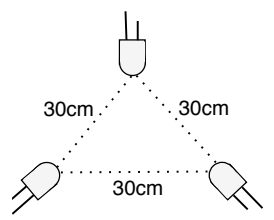

(b)

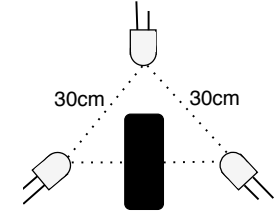

(c)

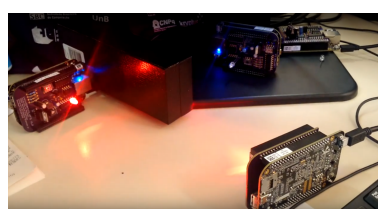

(d)

Figura 3. Cenários de experimentação estático (a) e dinâmicos (b) e (c) e foto do cenário em (d)

\subsection{Avaliação do cenário estático}

A figura 4 mostra o compromisso entre as tentativas médias de descoberta de rotas e o rendimento médio do protocolo, considerando diferentes contadores de referência(RC) e diferentes timeouts de rotas. Como pode ser observado, quando o protocolo é muito sensível e reage ao menor problema detectado, há um número alto de tentativas de descoberta e construção de rota. Amarrado a isso, a vazão média observada durante o experimento seria baixa, uma vez que há grande perda de tempo se estabelecendo rotas (e não transmitindo de fato).

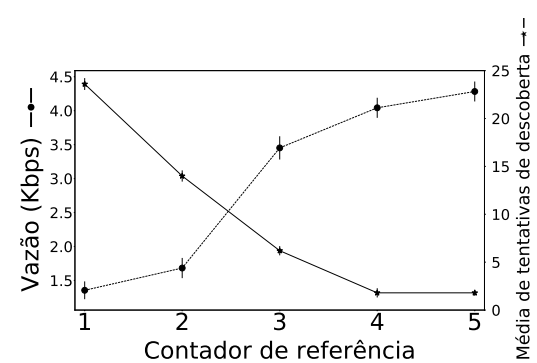

(a)

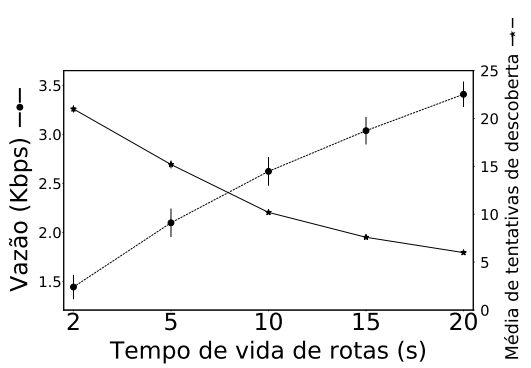

(b)

Figura 4. Compromisso entre as tentativas médias de descoberta de rotas e o rendimento médio.

De fato, na Figura 4a, pode ser observado que quando o protocolo reage ao primeiro problema percebido camada MAC (i.e. contador de referência $\mathrm{RC}=1$ ), há mais de 24 tentativas de construção de rota durante os experimentos. A vazão também obteve seu pior valor, ficando abaixo de 1,5 Kbps na média. Um padrão semelhante pôde ser observado para o DYRP-RT, apresentado na Figura 4b. Quanto menor o timeout estabelecido,

\footnotetext{
${ }^{4}$ https: / /photos.app.goo.gl/HnyzMpHK7tGyNs 798, 2018.
} 
maior a quantidade de tentativas de descoberta de rotas, o que diminui consideravelmente o desempenho da rede. Quanto maior o parâmetro de timeout, mais estável a rede fica.

\subsection{Avaliação do cenário dinâmico}

As figuras 5 e 6 apresentam a vazão média do sistema quando o contador de referência RC $=2$ e $\mathrm{RC}=5$, respectivamente. Como esperado, quando o obstáculo é adicionado ao cenário, a rede apresenta uma taxa de transferência menor. Isso ocorre devido a dois fatores principais: em primeiro lugar, os dados devem ser encaminhados pelo nó intermediário, o que causa um atraso na entrega da mensagem. Em segundo lugar, mais falhas de enlace ocorrem pois a fonte luminosa do intermediário pode interferir na fonte luminosa do nó de origem. Por fim, observamos que tão logo o obstáculo é removido, o desempenho da rede aumenta. Após o período de reação, o cenário com $\mathrm{RC}=5$ tem melhor desempenho quando comparado com o $\mathrm{RC}=2$. Nesse caso, o cenário dinâmico com $\mathrm{RC}=5$ teve vazão média de 4,69 Kbps em uma comunicação com 2 saltos.

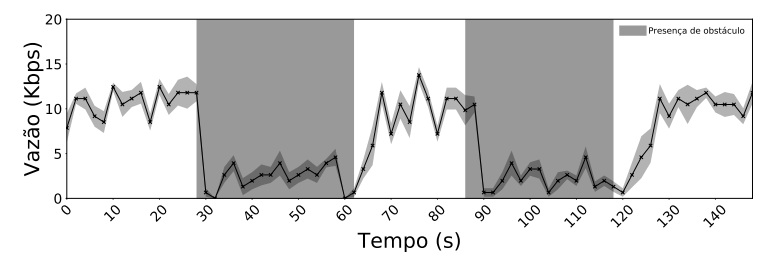

Figura 5. Desempenho da rede para o mecanismo DYRP-RC $(R C=2)$.

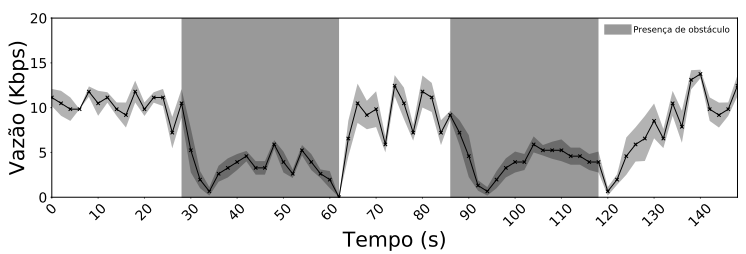

Figura 6. Desempenho da rede para o mecanismo DYRP-RC $(R C=5)$.

As figuras 7 e 8 apresentam os resultados para o cenário dinâmico em que o mecanismo DYRP-RT foi utilizado. Primeiramente, é possível observar que o a comunicação direta possui um desempenho pior, se comparada ao DYRp-RC. Isso ocorre devido aos tempos de vida associados as rotas. Em outras palavras, por mais que uma rota esteja ativa e estável, de tempos em tempos o algoritmos irá reconstruir a rota até o destino. Outro fator interessante que mostra o impacto do DYRP-RT pode ser observado para RT $=20$, durante os tempos 30 s e 40 s e 90 s e 100 s. Há uma queda brusca na vazão devido ao fato de adicionar um obstáculo antes da rota ser reconstrúída.

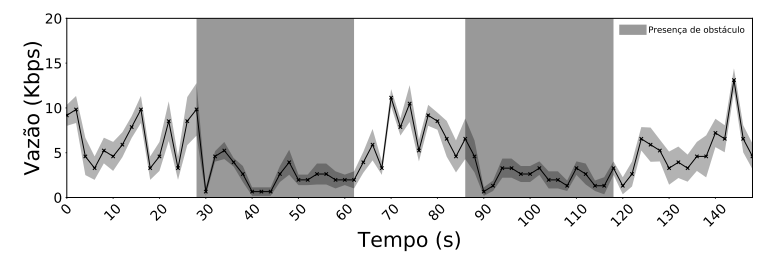

Figura 7. Desempenho da rede para o mecanismo DYRP-RT $(R T=5)$.

Ao comparar DYRP-RC e DYRP-RT, pode-se observar que o DYRP-RC oferece uma dinâmica mais adaptável às mudanças na rede, com reação mais clara e rápida. Por 


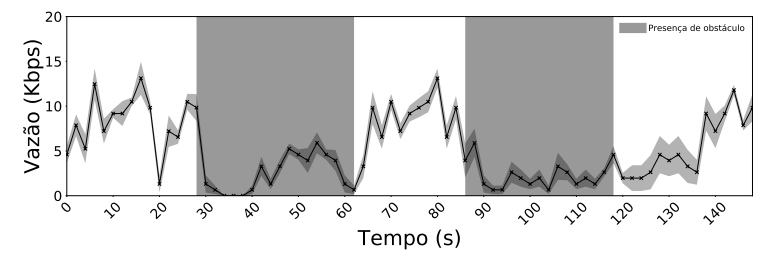

Figura 8. Desempenho da rede para o mecanismo DYRP-RT $(\mathrm{RT}=\mathbf{2 0})$.

outro lado, o DYRP-RT pode apresentar grandes lacunas de reação por depender apenas do tempo de vida das rotas estabelecidas. Também é possível observar que o DYRP-RC, dependendo do parâmetro escolhido, pode apresentar muitas falhas devido a tentativas sucessivas de construção de rotas causadas principalmente por problemas momentâneos.

\subsection{Avaliação de sobrecarga}

Foi criado um modelo analítico da sobrecarga imposta pelo protocolo. Além disso, foram realizadas medições durante os experimentos realizados para computar a sobrecarga imposta pelo protocolo. A decisão de quebrar uma rota é tomada através de parâmetros específicos do protocolo (timeout de rotas e contador de referência). Dependendo da frequência em que rotas são quebradas e tentativas de construção de novas rotas são realizadas, há um impacto na rede em termos de sobrecarga. As figuras 9a e 9b apresentam os resultados obtidos para os dois mecanismos abordados.

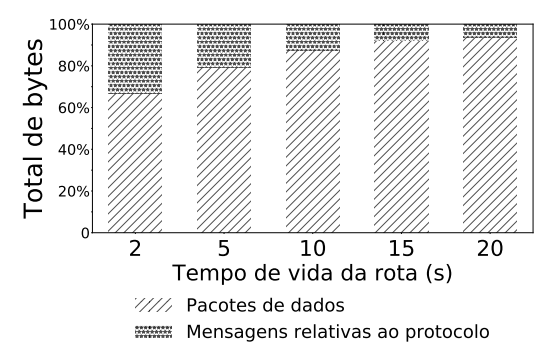

(a) Sobrecarga do DYRP-RT para um cenário de dois saltos

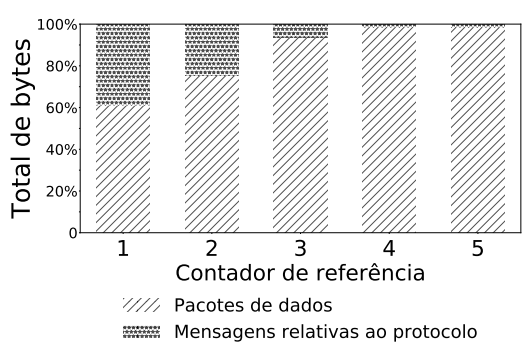

(b) Sobrecarga do DYRP-RC para um cenário de dois saltos

Figura 9. Resultados obtidos para o cenário estático.

Quanto maior o valor do parâmetro de referência da camada de enlace (RC), menor a sobrecarga na rede. E.g., para $\mathrm{RC}=1$, a sobrecarga chega a ser superior a $40 \%$. Nesse caso, o protocolo tem uma super-reação às perdas de dados na rede e, precocemente, interpreta como quebra de rotas. A mesma lógica funciona para o DYRP-RT, cujo impacto na rede é diretamente relacionadoaos parâmetros de timeout selecionados.

\section{Conclusões}

Nesta dissertação, foi apresentado o DYRP-VLC: um protocolo de roteamento dinâmico multi-camadas para Redes de Comunicação por Luz Visível. Nossa proposta se baseia em protocolos de roteamento reativos, em que rotas são contruídas e mantidas de acordo com as demandas da rede. Dois mecanismos de manutenção de rotas foram desenvolvidos: DYRP-RC, em que estatísticas da camada de enlace são utilizadas para decidir quando construir uma nova rota, e DYRP-RT, em que um tempo de vida é associado a 
cada rota criada. Ambos os mecanismos oferecem baixa sobrecarga para o cenário analisado (DYRP-RT apresenta menos de 10\%, enquanto o DYRP-RC oferece menos de 1\%). Em ambientes dinâmicos, o DYRP-RC apresentou resultados melhores, devido ao mecanismo dinâmico que ele apresenta.

\section{Publicações}

Destacamos as seguintes publicações: Um minicurso intitulado "Comunicação Por Luz Visível: Conceitos, Aplicações e Desafios" foi publicado na SBRC em 2017 [Matheus et al. 2017]. O envolvimento com comunicação bidirecional utilizando LEDs como receptores e transmissores gerou duas publicações, uma na SBESC [Matheus et al. 2018b] e outra no Internet Technology Letters [Matheus et al. 2018a]. Atualmente, temos um survey no terceiro round de avaliação no IEEE Surveys and Tutorials; um artigo submetido para uma edição especial da Ad Hoc Networks e um artigo submetido para o SBRC 2019. Esses fatos mostram a importância e a originalidade do trabalho realizado durante o mestrado.

\section{Referências}

Ahmad, Z., Rajbhandari, S., Salih, O., and Green, R. (2017). Demonstration of a multihop underwater visible light communication system. In IEEE ICTON.

De Vries, J. P., Simić, L., Achtzehn, A., Petrova, M., and Mähönen, P. (2014). The wifi "congestion crisis": Regulatory criteria for assessing spectrum congestion claims. Telecommunications Policy, 38(8):838-850.

Kaushal, H. and Kaddoum, G. (2016). Underwater optical wireless communication. IEEE Access, 4:1518-1547.

Kim, H.-J., Tiwari, S. V., and Chung, Y.-H. (2016). Multi-hop relay-based maritime visible light communication. Chinese Optics Letters, 14(5):050607.

Klaver, L. and Zuniga, M. (2015). Shine: A step towards distributed multi-hop visible light communication. In IEEE MASS.

Li, L., Hu, P., Peng, C., Shen, G., and Zhao, F. (2014). Epsilon: A visible light based positioning system. In NSDI, pages 331-343.

Matheus, L., Pires, L., Vieira, A., Vieira, L. F. M., Vieira, M. A. M., and Nacif, J. A. (2018a). The internet of light: Impact of colors in led-to-led visible light communication systems. Internet Technology Letters, 0(0): e78.

Matheus, L., Pires, L., Vieira, A., Vieira, M., Vieira, L. F., and Nacif., J. A. M. (2018b). Análise do impacto de diferentes cores na transmissão de dados por luz visível em dispositivos embarcados baseados em LEDs .

Matheus, L. M., Vieira, A. B., Vieira, L. F., Vieira, M., Freire, J., and Gnawali, O. (2017). Comunicação por luz visível: conceito, aplicações e desafios. In SBRC - Minicursos.

Okada, S., Yendo, T., Yamazato, T., Fujii, T., Tanimoto, M., and Kimura, Y. (2009). On-vehicle receiver for distant visible light road-to-vehicle communication. In IEEE Intelligent Vehicles Symposium.

Wang, Q., Zuniga, M., and Giustiniano, D. (2016). Passive communication with ambient light. In Proceedings of the 12th International on Conference on emerging Networking EXperiments and Technologies, pages 97-104. ACM.

Xiang, Y., Zhang, M., Kavehrad, M., Chowdhury, M. S., Liu, M., Wu, J., and Tang, X. (2014). Human shadowing effect on indoor visible light communications channel characteristics. Optical Engineering, 53(8):086113. 